\title{
Cadaver Study on the Branching Pattern of the Splenic Artery in a Bangladeshi Population
}

\author{
Alim $\mathrm{A}^{1}$, Nurunnabi ASM ${ }^{2}$, Mahbub $\mathrm{S}^{3}$, Ahmed $\mathrm{R}^{4}$, Ara $\mathrm{S}^{5}$
}

\begin{abstract}
The spleen is the largest single mass of lymphoid tissue in all vertebrates. Arterial blood supply correlates with the functional capability of the human spleen. A cross-sectional, descriptive type of study was done in the Department of Anatomy, Dhaka Medical College, Dhaka, from January to December 2008, to see the arterial pattern in the human spleen. 30 human spleens were collected from the unclaimed dead bodies that were under examination in the Department of Forensic Medicine of Dhaka Medical College, Dhaka. The samples were divided into three age-groups including group A (15-29 years), group B (30-49 years) \& group $C$ (50-69 years). Then macroscopic dissection was done and radiological angiograph was taken to see the arterial pattern in the human spleen. The splenic artery was the origin of sole blood supply in all the specimens. Two lobar branches were found in $70 \%$ of specimens and three branches in 23\%. Four lobar branches were evident in only 2 specimens. Moreover, several segmental branches and polar arteries were found in the spleen of different ages. The distance between the splenic artery (before giving its lobar branches) and the hilum of the spleen were found $2.99 \pm 0.73 \mathrm{~cm}, 3.79 \pm 1.43 \mathrm{~cm}$ and $3.51 \pm 1.66 \mathrm{~cm}$ in group $A, B$ and $C$ respectively. However, the difference was not statistically significant among the study groups.
\end{abstract}

\section{Key words}

Spleen, arterial pattern of spleen, branches of splenic artery, angiogram of spleen.

\section{Introduction}

The spleen is the largest single mass of lymphoid tissue in humans ${ }^{1}$. Arterial blood supply correlates with the functional capability of the human spleen ${ }^{2}$. The splenic artery usually

1. Dr. Abdul Alim

Assistant Professor, Department of Anatomy

Khulna Medical College, Khulna

2. Corresponding Author : Dr. Abu Sadat Mohammad Nurunnabi Lecturer, Department of Anatomy

Dhaka Medical College, Dhaka

Email: shekhor19@yahoo.com

3. Dr. Sabiha Mahbub

Associate Professor, Department of Anatomy

Shahabuddin Medical College, Dhaka.

4. Dr. Rukshana Ahmed

Assistant Professor, Department of Anatomy

Faridpur Medical College, Faridpur.

5. Prof. Shamim Ara

Professor \& Head, Department of Anatomy

Dhaka Medical College, Dhaka. arises from the coeliac trunk to the right of the midline ${ }^{1}$. Jáuregui $^{3}$ found that the average length of splenic artery is $10.6 \mathrm{~cm}$. The most striking feature of the splenic artery is its tortuousity ${ }^{4}$. The spleen receives a generous blood supply. Approximately 350 liters of blood per day pass through the spleen $^{5}$. The spleen is structured in such a way that most of the blood flow passes through the marginal zone and directly along the white pulp leads to efficient monitoring of the blood by the immune system ${ }^{6,7}$ - as functional capacity correlates vascularity in the vicinity. Hence, the human spleen is an organ demanding constant attention from the anatomical, immunological and clinical point of view ${ }^{8}$. Sound knowledge of the variational anatomy of the splenic artery and its branches is indispensable to the surgeons in splenectomy, resection of any tumours, extirpation of cysts, because highly vascular spleen is prone to excessive bleeding which often occurs with resultant to unnecessary death ${ }^{4}$. The aim of the present study was to see the branching pattern of the splenic artery in the human cadaveric spleen. The findings of the study are expected to contribute to the knowledge pool on variational anatomy of the splenic arterial pattern.

\section{Materials \& Methods}

This cross-sectional, descriptive type of study was done in the Department of Anatomy, Dhaka Medical College, Dhaka, from January to December 2008. 30 human spleens were collected from the unclaimed dead bodies that were under examination in the Department of Forensic Medicine of Dhaka Medical College, Dhaka. The samples were brought to the Department of Anatomy and divided into three agegroups including group A (15-29 years), group B (30-49 years) \& group C (50-69 years), for convenience of the study procedure, according to Rayhan et al. ${ }^{9}$.

The splenic artery supplying the spleen and its branching pattern was observed by meticulous dissection on each specimen. The distance from the point of primary division of the splenic artery to the point of hilum was measured with the help of a measuring tape. Observed the number of lobar branches as most of the terminal division of the splenic artery occurs before entering into the hilum of the spleen. So was observed for lobar branches of the splenic artery by blunt macroscopic dissection. Its secondary branches were also observed. However, some of the lobar branches divided after entering into the hilum within the substance of splenic tissue. For this reason, 16 samples were transferred into the caustic soda solution for $24-48$ hours $(100 \mathrm{ml}$ water +25 gm caustic soda) after removal of splenic capsule from the surface of the spleen. The spleen were removed from the solution and washed thoroughly with running tap water. After that, the splenic tissue was removed by application of gentle pressure over it and washed with running tap water (according to Rayhan et al. ${ }^{9}$ ) (Fig. 1). 


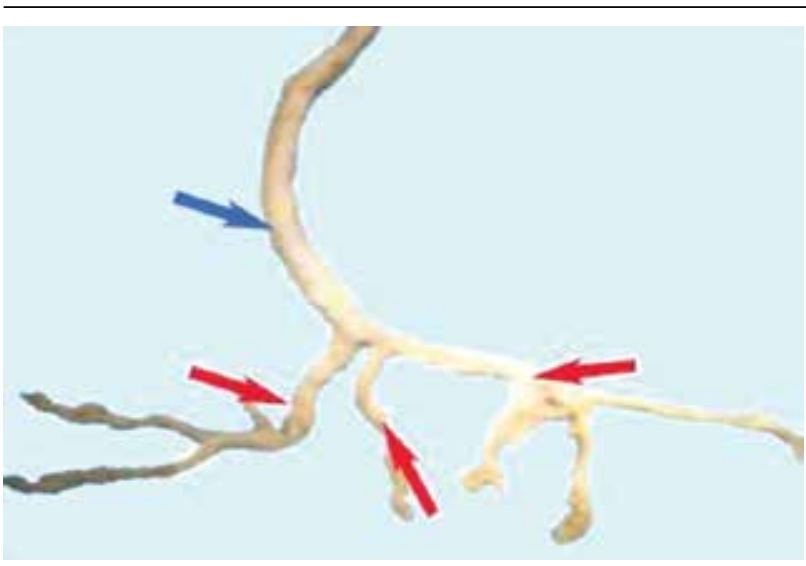

Fig. 1. Dissection of splenic artery and its branches (blue arrow- splenic artery, red arrow- lobar branches) in group A (15-29 years).

Angiography of spleen was done to see the vasculature especially for observing the number of the lobar branches and number of the secondary branches of the splenic artery. At first the tail of the pancreas was identified and the splenic artery was cut $5 \mathrm{~cm}$ proximal to the hilum of the spleen in 6 cases. The collected spleens were washed thoroughly with normal saline or acetone till the splenic vein showed the clear fluid coming out of it. Then solution of barium sulphate was injected into splenic artery with the help of a 50cc syringe and polythene cannula, but in few cases a branch of the splenic artery before entering to the hilum was ligated with silk to prevent the dye entering through that branch. The splenic artery was ligated after injecting the dye. The dye-injected spleens were radiographed immediately in more than two planes (according to Chakravarthi et al. ${ }^{7}$ ) (Fig. 2).

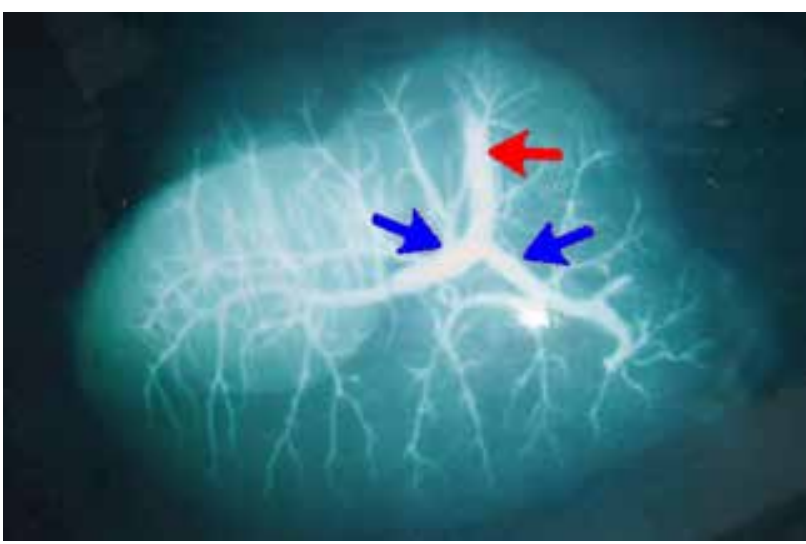

Fig. 2. Angiography of the human spleen (red arrow- splenic artery, blue arrow- lobar branches) in group B (30-49 years).

The collected data were analyzed by using SPSS version 11.0. Comparison between groups were done by One-way ANOVA (PostHoc). This research work was approved by the Ethical Review Committee of Dhaka Medical College, Dhaka.

\section{Results}

The splenic artery was the origin of sole blood supply in all the specimens. Two lobar branches were found in $70 \%$ of specimens and three lobar branches in $23 \%$. Four lobar branches were evident in only 2 specimens. Besides, several segmental branches and polar arteries were found in the spleen of different ages. The distance between the splenic artery (before giving its lobar branches) and the hilum of the spleen were found $2.99 \pm 0.73 \mathrm{~cm}, 3.79 \pm 1.43 \mathrm{~cm}$ and $3.51 \pm 1.66 \mathrm{~cm}$ in group $\mathrm{A}, \mathrm{B}$ and $\mathrm{C}$ respectively. The difference was not statistically significant among the study groups (Table-I, Fig. 3).

Table-I: Distance between splenic artery (before giving its lobar branches) and the hilum in different age group

\begin{tabular}{ccc}
\hline Group & $\begin{array}{c}\text { Distance between splenic artery } \\
\text { (before giving its lobar branches) } \\
\text { and the hilum in cm (Mean } \pm \text { SD) }\end{array}$ & P value \\
\hline A & $2.99 \pm 0.73$ & A vs B \\
$(\mathrm{n}=14)$ & $(2.29-4.83)$ & $>0.10^{\mathrm{ns}}$ \\
$\mathbf{B}$ & $3.79 \pm 1.43$ & $\mathbf{A}$ vs C \\
$(\mathrm{n}=11)$ & $(2.03-6.35)$ & $>0.10^{\mathrm{ns}}$ \\
$\mathbf{C}$ & $3.51 \pm 1.66$ & B vs C \\
$(\mathrm{n}=5)$ & $(2.29-6.35)$ & $>0.50^{\mathrm{ns}}$ \\
\hline
\end{tabular}

Figures in parentheses indicate range. Comparison between different group done by One-way ANOVA (PostHoc), ns = not significant.

Group A: Age 15 - 29 years

Group B: Age $30-49$ years

Group C: Age $50-69$ years

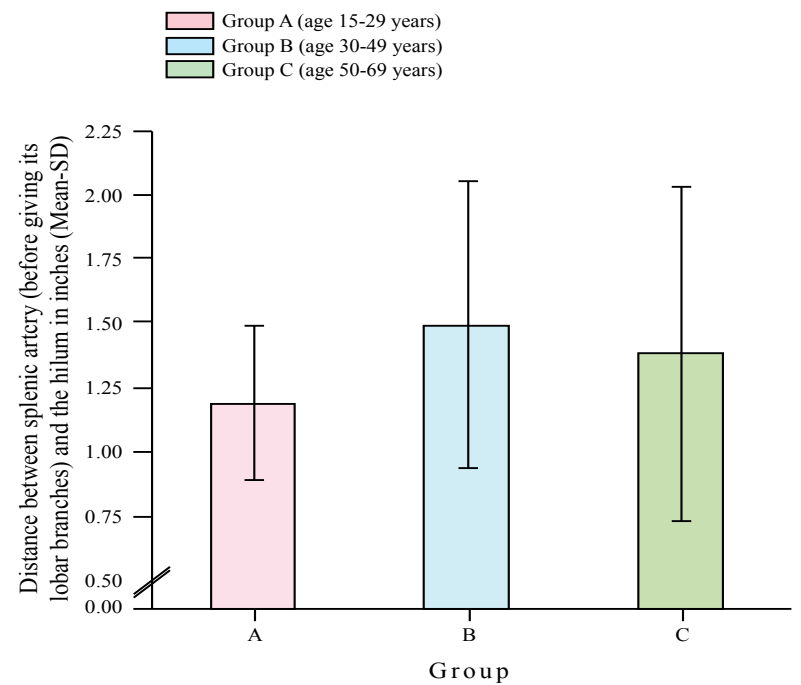

Fig. 3. Distance between splenic artery (before giving its lobar branches) and hilum of spleen in different age group.

\section{Discussion}

Splenic artery is divided into four segments suprapancreatic, pancreatic, pre pancreatic and prehilar segment ${ }^{8}$. The linear branches exhibit much marked variations. Striking peculiarities of the linear branches are prevailingly sudden rectangular origin and number of arteries entering the spleen varies from five to twenty, average eleven ${ }^{3,4,10}$. The size of the spleen does not determine the number of entering arteries ${ }^{3}$. The splenic artery is usually divided into an upper and lower main branches; these are known as the upper lobar and lower lobar artery ${ }^{2-4,9-12}$. Many investigators reported a third terminal branch, known as middle lobar artery ${ }^{3,4,11}$. However, all the lobar branches of the splenic trunk undergo subdivision into segmental branches. Gupta et al. ${ }^{2}$ studied 42 specimens 
where they found in $34(84 \%)$ specimens, the splenic artery divided into two primary branches and in 8 specimens $(16 \%)$ into three primary branches. Machálek et al. ${ }^{8}$ observed that the splenic artery in $79 \%$ of cases branches into superior and inferior splenic branch. Trifurcation was noticed in $18 \%$ cases. Rayhan et al. ${ }^{9}$ studied 70 cadaveric spleen and found two lobar arteries in $42(60 \%)$ and three lobar arteries in 28 $(40 \%)$ cases. Katritsis et al. ${ }^{10}$ stated that splenic artery is divided into two primary splenic branches in $85.7 \%$ of the specimens, and into three primary splenic branches in 14.3 $\%$ of the specimens. Liu et al. ${ }^{11}$ studied 850 specimens of spleen; the splenic artery had a single lobar artery in $0.8 \%$, two lobar arteries in $86 \%$, three lobar arteries in $12.2 \%$ and multiple lobar arteries in $1 \%$ cases. Sahni et al. ${ }^{12}$ stated that the splenic artery divided into two lobar branches in 135 out of $156(80 \%)$ male and 35 of $44(79.5 \%)$ female specimens. In remaining specimens, it divided into three lobar branches. Our findings are more or less similar to those of previous stiudies $^{2,8-12}$.

Sometimes the polar artery supplies the spleen without passing through the hilum ${ }^{12}$. Chakravarty et al. ${ }^{7}$ observed the upper polar arteries in $56 \%$ of the male and $27 \%$ of the female spleen and lower polar arteries in $28 \%$ of the male and $39 \%$ of the female spleen. Katritsis et al. ${ }^{10}$ described that $60 \%$ of superior and $80 \%$ of inferior polar arteries arose from the splenic artery or one of its primary branches. Liu et al. ${ }^{11}$ observed $31 \%$ of superior and $38 \%$ of inferior arteries in their study. Sahni et al. ${ }^{12}$ found the superior polar artery in $65 \%$ of the cases and the inferior polar artery supplies lower pole or anterior end of the spleen, which was found in $88 \%$ of the spleen. Our macroscopic dissection and angiographic study also revealed several polar arteries in the spleen of different ages.

Machálek et al. ${ }^{8}$ observed that the splenic artery divided into its terminal branches approximately $2.8 \mathrm{~cm}(2-12.2 \mathrm{~cm})$ from the hilum. Rayhan et al. ${ }^{9}$ also found that the distance between the splenic artery (before giving its lobar branches) and the hilum of the spleen were found $3.10 \pm 0.57 \mathrm{~cm}$ in group A (019 years), $3.24 \pm 0.65 \mathrm{~cm}$ in group $\mathrm{B}$ (20-29 years), $3.48 \pm 0.62$ $\mathrm{cm}$ in group C (30-39 years), $3.46 \pm 0.85 \mathrm{~cm}$ in group D (40-49 years), $3.16 \pm 0.71 \mathrm{~cm}$ in group $\mathrm{E}$ (50-59 years) and $3.50 \pm 0.51$ $\mathrm{cm}$ in group $\mathrm{F}$ ( $\geq 60$ years). However, the difference was not statistically significant among the study groups. Sahni et al. ${ }^{12}$ also stated that splenic artery divided into its terminal branches $2-4 \mathrm{~cm}$ proximal to the hilum of the spleen. Our results of are similar to those of previous investigators ${ }^{8,9,12}$.

The human spleen is divided accordingly into two or three main arterial segments, separated by a definite avascular plane. Each main segment is also subdivided, usually into two to four less constant secondary segments, the architecture of which and the avascular planes between them are very variable. The findings of this study may be regarded as an anatomical basis for highly conservative surgical management, as an alternative to splenectomy, in cases of splenic rupture or any space occupying lesion. Further studies with larger samples and corrosion-casts are recommended.

\section{Acknowledgement}

We would like to express our gratitude to the authority of the Health, Nutrition \& Population Sector Programme (HNPSP) of Directorate General Health Services (DGHS) of the Government of the People's Republic of Bangladesh, and Dhaka Medical College, Dhaka, for providing us with the grant for research.

\section{References}

1. Borley NR, Spleen. In: Standring S, Ellis H, Healy JC, Johnson D, Williams A, Collins P, et al. eds. Gray's anatomy: the anatomical basis of clinical practice. $39^{\text {th }}$ ed. Edinburgh: Elsevier Churchill Livingstone; 2005: p. 1239-44.

2. Gupta CD, Gupta SC, Arora AK, Singh PJ. Vascular segments in the human spleen. J Anat 1976; 121(3): 613-6.

3. Jáuregui E. Anatomy of the splenic artery [Article in Spanish]. [Abstract]. Rev Fac Cien Med Univ Nac Cordoba 1999; 56(1): 21-41.

4. Michels NA. The variational anatomy of the spleen and splenic artery. Am J Anat 1942; 70(1): 21-72.

5. Coetzee T. Clinical anatomy and physiology of the spleen. S Afr Med J 1982; 61(20): 737-46.

6. Mebius RE, Kraal G. structure and function of the spleen. Nature Rev 2005; 5: 606-16.

7. Chakravarty S, Shamal S, Pandey SK. Avascular zone in the human spleen - sex difference. J Anat Soc India 2003; 52(2): 150-1.

8. Machálek L, Holibková A, Tůma J, Houserková D. The size of the splenic hilus, diameter of the splenic artery and its branches in the human spleen. Acta Univ Palacki Olomuc Fac Med 1998; 141(1): 45-8.

9. Rayhan KA, Ara S, Kishwara S, Begum M, Begum GN, Shahriah S. Anatomy of the branches of the splenic artery - a postmortem study. Bangladesh J Anat 2007; 5(2): 61-5.

10. Katritsis E, Parashos A, Papadopoulos N. Arterial segmentation of the human spleen by post-mortem angiograms and corrosion-cast. Angiology 1982; 33(11): $720-7$.

11. Liu DL, Xia S, Xu W, Ye Q, Gao Y, Qian J. Anatomy of vasculature of 850 spleen specimens and its application in partial splenectomy. Surgery 1996; 119(1): 27-33.

12. Sahni AD, Jit BI, Gupta CNM, Gupta DM, Harjeet E. Branches of the splenic artery and splenic arterial segments. Clin Anat 2003; 16(5): 371-7. 